\title{
Effect of Sildenafil Citrate on Uterine Artery Blood Flow in Patients with Unexplained Recurrent Miscarriages: A Randomized Clinical Trial
}

Mohamed A. Mohamed, Assem A. Moussa, Hazem M. El-Taybe

Department of Obstetrics and Gynecology Faculty of Medicine - Al-Azhar University

Corresponding author: Hazem M. El-Tayb; Email: hazemeltaib20@yahoo.com; Mobile: 01111842709

\begin{abstract}
Background: Unexplained recurrent miscarriage can be a challenging and frustrating condition for both patients and clinicians. Sildenafil citrate is one of the currently available lines of treatment according to simplicity of use, reliability and degree of invasiveness but up to now there are no prospective randomized studies, powerful enough. Aim of this Work: To evaluate the efficacy of oral sildenafil citrate $20 \mathrm{mg}$ on uterine arteries Doppler flow studies in patients with unexplained recurrent miscarriages.

Patients and Methods: This prospective case control study was conducted at Sayed Galal Maternity Hospital outpatient clinics on 180 women who' were divided into 2 groups: (group 1) which included 91 patients who took sildenafil citrate $20 \mathrm{mg}$ orally, 4 times per day for 21 days and (group 2) which included 89 patients who took placebo orally, 4 times per day for 21 days in the period starting from (August 2017 to June 2018). Results: The statistical comparison between group I (sildenafil citrate) and group II (placebo) before and after administration of drug regarding endometrial thickness showed non-significant difference before and significant difference after 3 weeks of administration of sildenafil citrate in group I and placebo in group II. The statistical comparison in patients in group I (sildenafil citrate) before and after 1 week, 2 weeks and 3 weeks administration of drug regarding pulsatility index, resistance index and systolic/diastolic ratio showed significant difference. Conclusion: Sildenafil citrate has an effective role in increasing the uterine arteries blood flow in patients with recurrent miscarriage.
\end{abstract}

Keywords: Sildenafil Citrate, uterine artery blood flow, unexplained recurrent miscarriages.

\section{INTRODUCTION}

Repeated abortion is the loss of three or more consecutive pregnancies before the $24^{\text {th }}$ week of pregnancy. Either primary (women without a preexisting baby) or secondary (women with at least one pre-existing infant $)^{(\mathbf{1})}$. It affects about $0.5-1 \%$ of pregnant women. Allover for most women who experience miscarriage, the recurrence rate is below $30 \%$ and the chance of live birth after three consecutive losses is only $35 \%-45 \%{ }^{(2)}$.

The causes of repeated miscarriage are still unclear. The causes in the majority of cases, excluding the anatomical, genetic, microbiological and hormonal causes of abortion and full medical, surgical and social history, remain unknown ${ }^{\left({ }^{(3)}\right.}$.

Endometrial growth seems to be dependent on uterine artery blood flow and the importance of endometrial development on pregnancy outcome has been reported ${ }^{(4)}$.

The quality of the endometrium is an important factor in achieving successful implantation. A typical trilaminar appearance with a minimum thickness of $7 \mathrm{~mm}$ and a uterine artery pulsatility index of $<3.0$ are regarded as sound markers of endometrial receptivity ${ }^{(5)}$.

Several regimens were proposed to improve a poor endometrial response, including treatment with estrogen and low dose aspirin, while in past few years much interest was focused on role of nitric oxide as a modulator of uterine blood flow ${ }^{(6)}$. It was demonstrated that oxidative stress (nitric oxide and malondialdehyde), as well as tumor necrosis factor- $\alpha$, have a detrimental effect on pregnancy ${ }^{(7)}$.

Sildenafil citrate is a type 5-specific phosphodiesterase inhibitor, augments the vasodilator effect of nitric oxide by preventing the degradation of cyclic guanosine monophosphate. It has been used with great success in the treatment of male erectile dysfunction (4). The effect of sildenafil was evaluated on endometrial development in women who had thin endometrium; improved endometrial development was achieved among 70\% of cases. Among these women, a $29 \%$ ongoing pregnancy rate was achieved ${ }^{(\mathbf{8})}$.

The use of sildenafil citrate in women with unexplained recurrent abortions showed that the drug helped to improve the uterine artery blood flow and endometrial thickness ${ }^{(4)}$.

\section{Aim of the Work}

The aim of this study is to evaluate the efficacy of oral sildenafil citrate $20 \mathrm{mg}$ on uterine arteries Doppler flow studies (including endometrial thickness, pulsatility index, resistance index and systolic/ diastolic ratio) in patients with unexplained recurrent miscarriages.

\section{PATIENTS AND METHODS}

This prospective, randomized, double blinded study was made at Sayed Galal Maternity Hospital, starting from August 2017 to June 2018.

It included 180 patients with three or more unexplained recurrent miscarriages who were randomly allocated (computer based randomization 
using random allocation software ${ }^{\circledR}$ version 1.0 .0 ) to receive either:

- Sildenafil citrate $20 \mathrm{mg}$ orally, 4 times per day for 21 days (respatio (R) $20 \mathrm{mg}$ Pharma Right, Inc, Cairo, Egypt) starting from second day of menstrual cycle or

- Matching placebo orally, 4 times per day for 21 days starting from second day of menstrual cycle.

- Randomization codes were placed in sequentially numbered, opaque, sealed envelopes to be opened at time of ennoblement by an investigator who prepared the study drug and had no further involvement with the patient's care. All data were analyzed before it is determined which group is receiving sildenafil citrate and which is receiving placebo.

Sample size was calculated using a power of $80 \%$, an alpha of 0.05 , an expected 0.34 reduction in the uterine arteries pulsatility index values, and assumed standard deviation of 0.47 , based on a previous report of the uterine artery pulsatility index in a population of women similar to our population ${ }^{(9)}$. A sample size of 62 patients was calculated to be necessary, using these assumptions. A total number of 180 patients were recruited to compensate for possible drop-outs.

All women with recurrent miscarriages had systematic investigations according to the established protocol including hysteron-salpingogram, coagulation profile, thyroid function test, pelvic ultrasound scan, anticardiolpin antibodies IgG and IgM, lupus anticoagulant antibodies, and hormonal analysis (including progesterone, prolactin, androgens, and early follicular FSH, and LH).

\section{Inclusion criteria were:}

Age 18-35 years, Three or more recurrent miscarriages before the $24^{\text {th }}$ week of gestation with no apparent cause for their previous losses, Three or more months have elapsed since the last abortion, Postmenstrual period, No other, therapy allowed during our treatment course.

\section{Our exclusion criteria were:}

1- Concomitant use of organic nitrites, or nitrate, 2- Severe hepatic, renal, or cardiovascular impairment, 3- History of stroke or myocardial infarction, 4- Patients with retinitis pigmentosa were excluded from the study.

\section{Informed consent:}

An approval of the study was obtained from Al- Azhar University academic and ethical committee.

\section{Every patient was subjected to RESULTS}

Table (1): Statistical comparison between group I (sildenafil citrate) and group II (placebo) before
1- Verbal consent about the experimental nature of treatment prior to initiation of therapy.

2- Detailed past, family, and obstetric histories.

3- Questionnaire about possible side effects:

i- Common effects: headache, flushing, dyspepsia, nasal congestion, blurring of vision, photophobia, cyanopsia (blue vision), dizziness, postural hypotension, and urinary tract infection.

ii- Other minor effects: palpitations, diarrhea, vomiting, sweating, backache, and arthralgia.

iii- Rare serious effects: loss of peripheral vision, allergic reaction, sudden hearing loss, and chest pain.

4- Ultrasonography and pulsed Doppler blood flow assessments, using a Medison (Sonoace X6, South Korea) scanner with a transvaginal multifrequency probe, was performed 4 times, before intervention on weekly basis by the same operator, to measure:

a- Maximum endometrial thickness (calculated as the maximum distance between each myometrial/ endometrial interface through the central longitudinal axis of the uterus and with the calipers place don't eh outer walls of the endometrium).

b- Uterine arteries blood flow studies including:

i. Systolic/diastolic ration which reflects intrinsic resistance of the uterine artery.

ii. Pulsatility index (calculated as the difference between the peak systolic and end-diastolic velocities divided by the mean velocity during the cardiac cycle) which is a measure of the variability of blood velocity in the uterine artery.

iii. Resistance index (calculated as the difference between the peak systolic and end-diastolic velocities divided by the peak systolic velocity) which is an indicator of the resistance of uterine artery to perfusion.

\section{Statistics}

Statistical presentation and analysis of the present study was conducted, using the mean, standard error, unpaired student t-test, which was used to compare between two groups in quantitative data. Chi-square test was used to compare between groups in qualitative data, Fisher's exact test and Yates' corrected chi-square were computed for $2 \times 2$ tables. Analysis of variance [ANOVA] was used for comparison among different times in the same group in quantitative data. Linear correlation coefficient was also calculated. Calculation was computed by the computer program SPSS, V 17 for Windows. 
administration of drug regarding past history.

\begin{tabular}{|l|c|c|c|}
\hline \multirow{2}{*}{} & \multicolumn{3}{|c|}{ Groups } \\
\cline { 2 - 4 } & Group I (n=91) & Group II (n=89) & P value \\
\hline Age (years \pm SD) & $27.52 \pm 6.25$ & $27.53 \pm 5.04$ & 0.991 \\
\hline Duration of marriage & $5.57 \pm 4.34$ & $5.92 \pm 4.22$ & 0.579 \\
\hline Maternal smoking & $16(17.6 \%)$ & $15(16.9 \%)$ & 0.843 \\
\hline Previous labour & $0.70 \pm 0.86$ & $0.76 \pm 0.91$ & 0.645 \\
\hline Previous abortion & $3.78 \pm 2.33$ & $3.62 \pm 1.76$ & 0.599 \\
\hline Past history DM. & $16(17.6 \%)$ & $12(13.5 \%)$ & 0.448 \\
\hline Circumcision & $72(79.1 \%)$ & $73(82.0 \%)$ & 0.623 \\
\hline
\end{tabular}

Values are giving as Mean \pm SD or number (percent)

This statistical comparison between group I (sildenafil citrate) and group II (placebo) before administration of drug regarding past history shows non significant difference.

Table (2): Statistical comparison between group I (sildenafil citrate) and group II (placebo) before administration of drug regarding our routine laboratory investigations for any patients with unexplained recurrent abortion.

\begin{tabular}{|c|c|c|c|c|c|c|c|}
\hline & \multicolumn{7}{|c|}{ Groups } \\
\hline & \multicolumn{3}{|c|}{$\begin{array}{c}\text { Group I } \\
(n=91)\end{array}$} & \multicolumn{3}{|c|}{ Group II (n=89) } & \multirow[t]{2}{*}{ P-value } \\
\hline & Mean & \pm & SD & Mean & \pm & SD & \\
\hline FSH $(\mathrm{mIU} / \mathrm{mL})$ & 7.37 & \pm & 2.47 & 7.76 & \pm & 2.49 & 0.292 \\
\hline $\mathrm{LH}(\mathrm{mIU} / \mathrm{mL})$ & 4.93. & \pm & 1.67 & 4.40 & \pm & 1.65 & $0.034 *$ \\
\hline $\mathrm{T} 3$ (ng/dl) & 29.57 & \pm & 7.46 & 38.02 & \pm & 8.84 & 0.056 \\
\hline $\mathrm{T} 4$ (ng/dl) & 8.78 & \pm & 7.47 & 8.44 & \pm & 7.28 & 0.753 \\
\hline TSH (mIU/L) & 2.39 & \pm & 1.11 & 2.92 & \pm & 5.19 & 0.349 \\
\hline Prolactin $(\mathrm{ng} / \mathrm{ml})$ & 12.56 & \pm & 4.76 & 11.58 & \pm & 6.54 & 0.253 \\
\hline Anticardiolipin IgG (U/mL) & 1.09 & \pm & 0.29 & 1.05 & \pm & 0.21 & 0.250 \\
\hline Anticardiolipin (IgM U/mL) & 1.09 & \pm & 0.29 & 1.09 & \pm & 0.29 & 0.963 \\
\hline PTT (seconds) & 34.15 & \pm & 2.61 & 33.62 & \pm & 2.28 & 0.111 \\
\hline INR & 1.04 & \pm & 0.08 & 1.03 & \pm & 0.08 & 0.403 \\
\hline
\end{tabular}

\section{* = Significant, $P<0.05$}

All cases were negative regarding lupus anticoagulant.

This statistical comparison between group 1 (sildenafil citrate) and group II (placebo) before administration of drug regarding past history shows significant difference in LH.

Table (3): Statistical comparison between group I (sildenafil citrate) and group II (placebo) before administration of drug regarding expected sildenafil citrate side effects

\begin{tabular}{|l|c|c|c|c|c|}
\hline \multirow{2}{*}{\multicolumn{1}{c|}{ Before }} & \multicolumn{6}{c|}{ Groups } \\
\cline { 2 - 6 } & \multicolumn{2}{|c|}{ Group I (n=91) } & \multicolumn{2}{c|}{ Group II (n=89) } & P-value \\
\cline { 2 - 6 } & $\mathbf{N}$ & $\mathbf{\%}$ & $\mathbf{N}$ & $\mathbf{\%}$ & \\
\hline Headache & 19 & 20.88 & 16 & 17.98 & 0.623 \\
\hline Flushing & 21 & 23.08 & 10 & 11.24 & $0.035^{*}$ \\
\hline Dyspepsia & 4 & 4.40 & 8 & 8.99 & 0.217 \\
\hline Nasal congestion & 26 & 28.57 & 18 & 20.22 & 0.193 \\
\hline Blurring of vision & 8 & 8.79 & 16 & 17.98 & 0.070 \\
\hline Dizziness, postural hypertension & 12 & 13.19 & 16 & 17.98 & 0.375 \\
\hline Vomiting, diarrhea & 11 & 12.08 & 10 & 10.98 & 0.763 \\
\hline Palpitations & 27 & 29.67 & 31 & 34.83 & 0.229 \\
\hline 'Sweating & 56 & 61.5 & 54 & 60.7 & 0.905 \\
\hline
\end{tabular}

\section{$*$ = Significant, $P<0.05$}

This statistical comparison between group I (sildenafil citrate) and group II (placebo) before administration of drug regarding expected sildenafil citrate side effects shows significant difference in flushing. Table (4): Statistical comparison between group I (sildenafil citrate) and group II (placebo) after administration of drug regarding expected sildenafil citrate side effects. 


\begin{tabular}{|l|c|c|c|c|c|}
\hline \multirow{2}{*}{ After } & \multicolumn{5}{c|}{ Groups } \\
\cline { 2 - 6 } & \multicolumn{2}{|c|}{ Group I (n=91) } & \multicolumn{2}{c|}{ Group II (n=89) } & P-value \\
\cline { 2 - 6 } & $\mathbf{N}$ & $\%$ & $\mathbf{N}$ & $\%$ & \\
\hline Headache & 43 & 47.25 & 24 & 26.97 & $0.005^{*}$ \\
\hline Flushing & 23 & 25.27 & 14 & 15.73 & 0.113 \\
\hline Dyspepsia & 4 & 4.40 & 8 & 8.99 & 0.217 \\
\hline Nasal congestion & 22 & 24.18 & 17 & 19.10 & 0.409 \\
\hline Blurring of vision & 23 & 25.27 & 20 & 22.47 & 0.659 \\
\hline Dizziness, postural hypertension & 32 & 35.16 & 36 & 40.45 & 0.465 \\
\hline Vomiting, diarrhea & 18 & 19.78 & 16 & 17.58 & 0.534 \\
\hline Palpitations & 40 & 44.0 & 35 & 39.33 & 0.529 \\
\hline Sweating & 60 & 65.9 & 56 & 62.9 & 0.673 \\
\hline
\end{tabular}

\section{* = Significant, $P<0.05$}

This statistical comparison between group I (sildenafil citrate) and group II (placebo) after administration of drug regarding expected sildenafil citrate side effects shows significant difference in headache.

Table (5): Statistical comparison in patients in group I (sildenafil citrate) before and after administration of drug regarding expected sildenafil citrate side effects

\begin{tabular}{|l|c|c|c|c|c|}
\hline \multirow{2}{*}{} & \multicolumn{6}{|c|}{ Group I (n=91) } \\
\cline { 2 - 7 } & \multicolumn{3}{|c|}{ Before } & \multicolumn{3}{|c|}{ After } & P-value \\
\cline { 2 - 7 } & $\mathbf{N}$ & $\mathbf{\%}$ & $\mathbf{N}$ & $\% / \mathbf{c}$ & \\
\hline Headache & 19 & 20.88 & 43 & 47.25 & $0.023^{*}$ \\
\hline Flushing & 21 & 23.1 & 23 & 25.3 & 0.729 \\
\hline Dyspepsia & 4 & 4.40 & 4 & 4.40 & 1.000 \\
\hline Nasal congestion & 26 & 28.57 & 22 & 24.18 & 0.331 \\
\hline Blurring of vision & 8 & 8.79 & 23 & 25.27 & 0.251 \\
\hline Dizziness, postural hypertension & 12 & 13.19 & 32 & 35.16 & 0.632 \\
\hline Vomiting, diarrhea & 11 & 12.08 & 18 & 19.78 & 0.156 \\
\hline Palpitations & 27 & 29.7 & 40 & 44.0 & $0.046^{*}$ \\
\hline Sweating & 56 & 61.5 & 60 & 65.9 & 0.537 \\
\hline
\end{tabular}

\section{* = Significant, $P<0.05$}

This Statistical comparison between patients in group I (sildenafil citrate) before and after administration of drug regarding expected sildenafil citrate side effects shows significanct difference in headache and palpitations.

Table (6): Statistical comparison in patients in group II (placebo) before and after administration of drug regarding expected sildenafil citrate side effects

\begin{tabular}{|l|c|c|c|c|c|}
\hline \multirow{2}{*}{} & \multicolumn{6}{|c|}{ Group II (n=89) } \\
\cline { 2 - 7 } & \multicolumn{3}{|c|}{ Before } & \multicolumn{3}{|c|}{ After } & P-value \\
\cline { 2 - 7 } & $\mathbf{N}$ & $\mathbf{\%}$ & $\mathbf{N}$ & $\mathbf{\%}$ & \\
\hline Headache & 16 & 17.98 & 24 & 26.97 & 0.707 \\
\hline Flushing & 10 & 11.24 & 14 & 15.7 & 0.349 \\
\hline Dyspepsia & 8 & 8.99 & 8 & 8.99 & 1.000 \\
\hline Nasal congestion & 18 & 20.22 & 17 & 19.10 & 0.816 \\
\hline Blurring of vision & 16 & 17.98 & 20 & 22.47 & 0.830 \\
\hline Dizziness, postural hypertension & 16 & 17.98 & 36 & 40.45 & $<0.001^{*}$ \\
\hline Vomiting, diarrhea & 10 & 10.98 & 16 & 17.58 & 0.204 \\
\hline Palpitations & 31 & 34.83 & 35 & 39.33 & 0.581 \\
\hline Sweating & 54 & 60.67 & 56 & 62.9 & 0.905 \\
\hline
\end{tabular}

\section{* = Significant, $P<0.05$}

This statistical comparison in patients in group II (placebo) before and after administration of drug regarding expected sildenafil citrate side effects shows significant difference in dizziness, postural hypertension.

Table (7): Statistical comparison between group I (sildenafil citrate) and group II (placebo) before 
administration of drug regarding pulsatility index, resistance index, systolic/diastolic ratio and endometrial thickness.

\begin{tabular}{|l|ccc|cccc|c|}
\hline \multirow{2}{*}{} & \multicolumn{7}{|c|}{ Before } \\
\cline { 2 - 8 } & \multicolumn{3}{|c|}{ Group I } & \multicolumn{3}{c|}{ Group II } & \\
\cline { 2 - 8 } & Mean & \pm & SD & Mean & \pm & SD & P-value \\
\hline Pulsatility index & 3.270 & \pm & 3.223 & 2.779 & & 1.175 & 0.178 \\
\hline Resistance index & 0.924 & \pm & 0.246 & 0.846 & \pm & 0.142 & 0.464 \\
\hline Systolic/ diastolic ratio & 5.747 & \pm & 3.963 & 4.713 & \pm & 1.765 & 0.070 \\
\hline Endometrial thickness: & 5.432 & \pm & 2.345 & 5.324 & \pm & 1.354 & 0.706 \\
\cline { 2 - 8 } - Before & 5.432 & \pm & 2.345 & 5.324 & \pm & 1.354 & 0.706 \\
\cline { 2 - 7 }$\quad$ - After 3 weeks & 11.124 & \pm & 2.657 & 10.465 & \pm & 1.425 & $0: 040^{*}$ \\
\hline
\end{tabular}

$*$ Significant, $P<0.05$

This statistical comparison between group I (sildenafil citrate) and group II (placebo) before administration of drug regarding pulsatility index, resistance index, systolic/diastolic ratio and endometrial thickness shows non significant difference.

This statistical comparison between group I (sildenafil citrate) and group II (placebo) before and after administration of drug regarding endometrial thickness shows non significant difference before and significant difference after 3 weeks of administration of sildenafil citrate.

Table (8): Statistical comparison in patients in group I (sildenafil citrate) before and after 1 week, 2 weeks and 3 weeks administration of drug regarding pulsatility index, resistance index and systolic/ diastolic ratio.

\begin{tabular}{|c|c|c|c|c|c|c|c|c|c|}
\hline \multirow{2}{*}{} & \multicolumn{9}{|c|}{ Group I (n=91) } \\
\cline { 2 - 11 } & \multicolumn{2}{|c|}{ Before } & \multicolumn{2}{c|}{$\begin{array}{c}\text { After } \\
\text { 1 week }\end{array}$} & \multicolumn{2}{c|}{ After 2 weeks } & \multicolumn{2}{c|}{ After 3 weeks } & \multirow{2}{*}{ P-value } \\
\cline { 2 - 11 } & Mean & SD & Mean & SD & Mean & SD & Mean & SD & \\
\hline Pulsatility index & 3.270 & 3.223 & 3.190 & 2.163 & 3.052 & 3.842 & 2.055 & 0.743 & $0.010^{*}$ \\
\hline Resistance index & 0.924 & 0.246 & 0.876 & 0.198 & 0.857 & 0.129 & 0.847 & 0.109 & $0.020^{*}$ \\
\hline $\begin{array}{c}\text { Systolic/ diastolic } \\
\text { ratio }\end{array}$ & 5.747 & 1.463 & 5.201 & 1.435 & 4.987 & 1.647 & 4.732 & 1.014 & $0.047^{*}$ \\
\hline
\end{tabular}

* = Significant, $P<0.05$

This statistical comparison in patients in group I (sildenafil citrate) before and after 1 week, 2 weeks and 3 weeks administration of drug regarding pulsatility index, resistance index and systolic/diastolic ratio shows significant difference.

Table (9): Statistical comparison in patients in group II (placebo) before and after 1 week, 2 weeks and 3 weeks administration of drug regarding pulsatility index, resistance index and systolic/diastolic ratio.

\begin{tabular}{|c|c|c|c|c|c|c|c|c|c|}
\hline & \multicolumn{9}{|c|}{ Group II (n=89) } \\
\cline { 2 - 11 } & \multicolumn{2}{|c|}{ Before } & \multicolumn{2}{c|}{$\begin{array}{c}\text { After } \\
\text { 1 week }\end{array}$} & \multicolumn{2}{c|}{$\begin{array}{c}\text { After } \\
\text { 2 weeks }\end{array}$} & After 3 weeks & $\begin{array}{c}\text { P- } \\
\text { value }\end{array}$ \\
\cline { 2 - 10 } & Mean & SD & Mean & SD & Mean & SD & Mean & SD & \\
\hline Pulsatility index & 2.979 & 1.175 & 2.314 & 1.642 & 2.519 & 1.354 & 2.434 & 1.256 & 0.365 \\
\hline Resistance index & 0.946 & 0.142 & 0.875 & 0.154 & 0.925 & 0.364 & 0.873 & 0.182 & 0.080 \\
\hline $\begin{array}{c}\text { Systolic/ diastolic } \\
\text { ratio }\end{array}$ & 4.913 & 1.765 & 4.242 & 1.642 & 4.426 & 1.649 & 4.527 & 1.795 & 0.157 \\
\hline
\end{tabular}

This statistical comparison in patients in group II (placebo) before and after 1 week, 2 weeks and 3 weeks administration of drug regarding pulsatility index, resistance index and systolic/diastolic ratio shows non significant difference. 
duration of marriage, previous labor, previous abortion, past history of DM, circumcision status between group I (sildenafil citrate) and group II (placebo) before drug administration. Also there was non statistical significant difference regarding laboratory investigations except that for $\mathrm{LH}(\mathrm{p}=$ 0.034).

El-Far et al. ${ }^{(7)}$ who evaluated and compared the serum levels of some antioxidants, tumor necrosis factor- $\alpha$, luteinizing hormone and follicle stimulating hormone in women with unexplained recurrent miscarriage through using 2 patient groups (16 women with abortions 3-5 and 24 women with abortions >5) and 2 control group (20 women within their first trimester of pregnancy and 20 non pregnant healthy females within their follicular phase), also found a significant increase in serum levels of LH between unexplained recurrent spontaneous miscarriage (URSM) groups compared to control groups $(\mathrm{p}<0.05)$.

Our results showed statistical significant difference in headache $(\mathrm{p}=0.023)$ and palpitations $(p=0.046)$ in group I (sildenafil citrate) after drug administration, while after drug administration dizziness $(\mathrm{p}<0.001)$, postural hypertension $(\mathrm{p}<$ 0.001 ) were significantly higher in group II (placebo).

Sildenafil citrate is indicated for the treatment of erectile dysfunction in men and may also play a role in some components of the female sexual arousal response, its main adverse effects were headache, flushing, rhinitis, nausea, visual disturbances, and dyspepsia, which were generally mild to moderate in nature ${ }^{\mathbf{( 1 0 )}}$.

In placebo-controlled clinical trials, the discontinuation rate due to adverse events for (sildenafil citrate) $(2.5 \%)$ was not significantly different from placebo (2.3\%). The adverse events were generally transient and mild to moderate in nature, and in another trial sildenafil citrate was taken as recommended (on an as-needed basis) in flexible-dose, placebo-controlled clinical trials, the adverse effects were moderate to mild as headache and palpitation but other adverse reactions occurred at a rate of $>2 \%$, but equally common on placebo and also was found to improve endometrial thickness significantly, which is especially important in successful implantation. Therefore, sildenafil citrate introduced vaginally might be a novel therapy improving the quality of the endometrium and the immunologic environment in patients with recurrent miscarriage ${ }^{(5)}$.

As regard Doppler indices (pulsatility index, resistance index and systolic/diastolic ratio) and endometrial thickness, the current study showed that there was statistically significant difference between group 1 and group 2 after drug administration in endometrial thickness $(\mathrm{p}=0.04)$.
The current study also showed that there was statistically significant difference in patients in group 1 before and after sildenafil administration in PI $(\mathrm{p}=0.01), \mathrm{RI}(\mathrm{p}=0.02)$ and $\mathrm{S} / \mathrm{D}(\mathrm{p}=0.047)$.

This results coincides with the results of Sher and Fisch ${ }^{(4)}$, who evaluated the effect of vaginal sildenafil on the outcome of in vitro fertilization (IVF) after multiple IVF failures attributed to poor endometrial development in a cohort of 105 infertile women aged $<40$ years, with normal ovarian reserve and at least 2 consecutive prior IVF failures attributed to inadequate endometrial thickness. Patients were given vaginal sildenafil suppositories in addition to gonadotrophin releasing hormone 20 mg, 4 times daily, for 3-10 days. The results of the mentioned study showed that vaginal sildenafil enhanced endometrial development in $70 \%$ of studied cases

The results of the current study goes with the results of Alatas and Yagci ${ }^{(11)}$, who studied the effect of single oral dose of $50 \mathrm{mg}$ sildenafil in 25 volunteer postmenopausal women who were subjected to color Doppler sonography before and 1 hour after administration of sildenafil. The study showed that RI was significantly lowered $(\mathrm{p}<0.001)$ and pulsatility index also was significantly lowered $(p<0.001)$. Findings of the current study was in agreement with El-Far $\boldsymbol{e t}$ al. ${ }^{(7)}$ who studied the effect of sildenafil as a novel treatment of threatened miscarriage in patients with a history of URSM. The mentioned study was carried out on 4 pregnant patients with history of URSM in their first trimester of pregnancy. In the 4 patients, $20 \mathrm{mg}$ sildenafil citrate tablets were inserted into the vagina 4 times per day for 24 days. The results evaluated changes in the concentrations of some antioxidants, the percent expression of cells positive for tumor necrosis factor$\alpha$, natural killer cells and uterine artery PI, and compared to the results of 4 healthy women in their first trimester of pregnancy. Using Doppler ultrasound, the study observed decreased values of $\mathrm{RI}(\mathrm{p}<0.05)$ and PI $(\mathrm{p}<0.05)$ of the uterine arteries in URSM following use of intravaginal sildenafil compared to healthy women in their first trimester of pregnancy.

Also, in agreement with our results, Hale et al. (12) who studied the effect of sildenafil on uterine artery blood flow in non-pregnant nulliparous women. In this study, 15 women were randomized in a double-blind fashion to receive either placebo or sildenafil $(25$ or $100 \mathrm{mg}$ ) during the luteal phase of the menstrual cycle, color Doppler ultrasound of both uterine arteries was performed at baseline and 1 and 3-hours post-dosing to evaluate RI and uterine volumetric flow, the results showed that those who received sildenafil significantly decreased RI $(\mathrm{p}=0.03)$. 
Animal models have been used to study the effect of sildenafil on uterine blood flow with varying results. Herraiz et al. ${ }^{(13)}$ in their study evaluateed perinatal outcome after sildenafil citrate administration at the onset of pregnancy in a rat pre-eclampsia model. Their results showed that sildenafil citrate restored normal values of blood pressure, cell count and proteinuria for maternal syndrome. In offspring, sildenafil citrate improved weight gain and increased survival rates without fetotoxic effects. According to the hemodynamic results, sildenafil citrate had a significant effect on the resistance index in the uterine artery in pre-eclamptic animals, as it restored normal values to correlate with an increase in fetal perfusion through the ductus venous.

On the other side, our study disagrees with Jerzak et al. ${ }^{(5)}$ in their study on thirty-eight nonpregnant women with a history of recurrent miscarriage (RM) and 37 healthy women with previous successful pregnancy outcomes patients self-administered sildenafil suppositories $(25 \mathrm{mg}$ intravaginally, four times a day) for 36 days. Peripheral blood NK-cell activity before and after vaginal sildenafil therapy in the RM women was measured using flow cytometry. In addition, uterine artery blood flow and endometrial thickness were recorded using Doppler ultrasound with an intravaginal probe. Endometrial thickness was significantly lower in the RM group compared with the control group $(8.06 \pm 2.74 \mathrm{~mm}$ vs. $9.03 \pm 3.34 \mathrm{~mm}$, respectively; $\mathrm{P}<.05)$. Endometrial thickness was significantly increased after vaginal sildenafil therapy compared with before therapy in the RM group $(9.25 \pm 2.23 \mathrm{~mm}$ vs.8.06 $\pm 2.74 \mathrm{~mm}$, respectively; $\mathrm{P}<.05$ ); however, we did not determine any significant differences in uterine artery PI before and after therapy (right uterine artery PI: $2.38 \pm 1.06$ vs. $2.26 \pm 0.60$; left uterine artery PI $2.30 \pm 0.69$ vs. $2.38 \pm 0.77$; respectively; $\mathrm{P}>.05$ ). There were no significant differences in uterine artery PI between the RM group and the control group (right uterine artery PI: $2.38 \pm 1.06$ vs. $2.37 \pm 0.36$; left uterine artery PI $2.30 \pm 0.69$ vs. $2.40 \pm 0.45$; respectively; $\mathrm{P}>.05)$.

\section{CONCLUSION}

Sildenafil citrate has an effective role in increasing the uterine arteries blood flow in patients with recurrent miscarriage.

\section{REFERENCES}

1. Quenby S, Vince G, Farquharson R, Aplin J (2002): Recurrent miscarriage: a defect in nature's quality control?. Human Reproduction, 17(8):195963.
2. El Hachem H, Crepaux V, May-Panloup $P$, Descamps P, Legendre G, Bouet PE (2017): Recurrent pregnancy loss: current perspectives. International Journal of Women's Health, 9:331.

3. El-Far M, Abd El Gawad EM, Ikbal AH, Nadia B (2009): Biochemical role of intravaginal sildenafil citrate as a novel antiabortive agent in unexplained recurrent spontaneous miscarriage: First' clinical Study of four case reports from Egypt. Clin Chem Lab Med., 47(11): 1433-1438.

4. Sher G and Fisch JD (2003): Effect of vaginal sildenafil on the outcome of in vitro fertilization (IVF) after multiple IVF failures attributed to poor endometrial development. Fertility and Sterility, 78(5):1073-6.

5. Jerzak M, Monika K, Mrozek J et al. (2008): Sildenafil citrate decreased natural killer cell activity and enhanced chance of successful pregnancy in women with a history of recurrent miscarriage. Fertility and Sterility, 90(5): 1848-1854.

6. Hurst BS, Bhojwani JT, Marshburn PB, Papadakis MA, Loeb TA, Matthews ML (2005): Low-dose aspirin does not improve ovarian stimulation, endometrial response, or pregnancy rates for in vitro fertilization. Journal of Experimental \& Clinical Assisted Reproduction, 2(1):8-14.

7. El-Far M, El Sayed IH, El Motwally AE et al. (2009): Serum levels of TNF- $\alpha$ and antioxidant enzymes and placental TNF- $\alpha$ expression in unexplained recurrent spontaneous miscarriage. J Physiol Biochem., 65(2): 175-182.

8. Paulus WE, Strehler E, Zhang M, Jelinkova L, ElDanasouri I, Sterzik K (2002): Benefit of vaginal sildenafil citrate in assisted reproduction therapy. Fertility and sterility, 77(4):846-7.

9. Lazzarin N, Vaquero E, Exacoustos C, Romanini E, Amadio A, Arduini D (2007): Midluteal phase Doppler assessment of uterine artery blood flow in nonpregnant women having a history of recurrent spontaneous abortions: correlation to different etiologies. Fertility and Sterility, 87(6):1383-7.

10. Basson R, McInnes R, Smith MD, Hodgson G, Koppiker N (2002): Efficacy and safety of sildenafil citrate in women with sexual dysfunction associated with female sexual arousal disorder. Journal of Women's Health \& Gender-based Medicine, 11(4):367-77.

11. Alatas E and Yagci AB (2004): The effect of sildenafil citrate on uterine and clitoral arterial blood flow in postmenopausal women. Department of obstetrics and gynecology, Pamukkale University Hospital, Denizli, Turkey Medscape General Medicine, 6(4): 51-55.

12. Hale SA, Jones CW, George O et al. (2010): Sildenafil increases uterine blood flow in nonpregnant nulliparous women. Reprod Sci., 17(4): 358-365.

13. Herraiz S, Pellicer B. Serra V et al. (2012): Sildenafil citrate improves perinatal outcome in fetuses from pre-eclamptics rats. BJOG., doi: $103111 / \mathrm{j}$. 